\title{
STUDENT SCIENCE WRITING COMPETITIONS AWARD WINNING PAPERS 2011 AND 2102
}

\section{1 \\ Winner}

\section{Scott Harroun ${ }^{1}$ :}

"Application of surface enhanced Raman Spectroscopy for the determination of chemical composition of paint samples from the historic Charles Morris Building in Halifax, Nova Scotia”.

\section{Honourable Mention}

\section{Carolanne Black:}

“Turbidity currents: A unique part of Nova Scotia's African geological heritage".

\section{2}

\section{Winner of the Graduate Prize}

\section{Suzuette Soomai:}

The use and influence of scientific information in environmental policy making: lessons learned from Nova Scotia.

\section{Undergraduate Winner}

\section{William Roberts ${ }^{1}$ :}

An overview of the biology, ecology, conservation and fishing industry of seahorses (Hippocampus spp.).

\footnotetext{
${ }^{1}$ These papers were unavailable in usable format at the time of publication and may be published at a later date.
} 


\section{Honourable Mention}

\section{Robert Paul':}

"The elusive causal association between gastro-esophageal reflux disease (GERD) or colon inflammation and atrial fibrillation (AFIB) and atrial flutter: A review of the literature and new case study." 